30 March 2016

\title{
The Use of Audio Playback to Deter Crop-raiding Asian Elephants
}

RH: Wijayagunawardane et al. • Vocalizations to Deter Crop-raiding Elephants

MISSAKA P. B. WIJAYAGUNAWARDANE, Department of Animal Science, University of Peradeniya 20400, Sri Lanka, and Department of Zoology, University of Melbourne, Melbourne, VIC 3010, Australia

ROGER V. SHORT, Department of Zoology, University of Melbourne, Melbourne, VIC 3010, Australia

THUSITH S. SAMARAKONE, Department of Animal Science, University of Peradeniya 20400, Sri Lanka

K. B. MADHUKA NISHANY, Department of Animal Science, University of Peradeniya 20400, Sri Lanka

HELENA HARRINGTON, Department of Zoology, University of Melbourne, Melbourne, VIC 3010, Australia

B. V. P. PERERA, Elephant Transit Home, Department of Wildlife Conservation, Udewalawe, Sri Lanka

ROGER RASSOOL, School of Physics, University of Melbourne, Melbourne, VIC 3010, Australia

EVAN P. BITTNER, ${ }^{1}$ Faculty of Veterinary and Agricultural Sciences, University of Melbourne, Melbourne, VIC 3010, Australia

${ }^{1}$ E-mail: bittnere@unimelb.edu.au

ABSTRACT Human-elephant conflict (HEC) and poaching are the foremost threats to the survival of elephants (African, Loxodonta africana; Asian, Elephas maximus) in their natural environments. Reducing HEC has the potential to save hundreds of elephant and human lives 
annually across Asia and Africa. Lone adult male elephants are the principal crop raiders; therefore, we investigated the effectiveness of a variety of audio playbacks at deterring 22 wild adult male Asian elephants from food sources in a wildlife reserve in southern Sri Lanka in January, 2011. Food was provided ad libitum, and the reactions of the elephants in response to various stimuli were recorded and analyzed. Vocalizations from a wild Asian elephant matriarchal group resulted in a flight response in $65 \%$ of trials conducted, in contrast to a control sound, a chainsaw, which produced no flight responses from any adult male. We demonstrated that audio playbacks could be used as a short-term deterrent to wild adult male Asian elephants from crop raiding; thus, providing a simple, natural, cost-effective and humane way of mitigating HEC.

KEY WORDS Asian elephant, human-elephant conflict, Sri Lankan hornet, vocalization.

(WILDLIFE SOCIETY BULLETIN 00(0):000-000; 201X)

African (Loxodonta africana) and Asian (Elephas maximus) elephant populations have been in decline over the past few decades as a result of a substantial increase in the human population (Perera 2009). Like many free-ranging populations of mammals with complex social systems, elephants already face severe human disturbance, which is only set to increase with projected worldwide anthropogenic environmental change (Shannon et al. 2013). Currently, there are approximately 40,000-50,000 Asian elephants left in the wild (IUCN 2012). This declining population is spread over small fragmented pockets of natural forest habitat in Southeast Asia. Currently, the greatest threat to wild Asian elephants is conflict with humans during raids on agricultural crops and villages within the elephants' home range, resulting in mutual slaughter (Fernando et al. 2008). Human-elephant Conflict (HEC) in Sri Lanka on average annually accounts for 151 elephant and 60 human deaths, with significant economic losses to rural farmers (Sooriyabandara 2014). There were approximately 5,000 
elephants left in Sri Lanka by 2011 (Fernando et al. 2011), with the human population expected to increase dramatically (Population Reference Bureau 2011), so the incidence of HEC threatens to increase in the future. Most HEC mitigation methods currently in use are aimed at establishing physical barriers that prevent elephants from reaching human settlements (Fernando et al. 2008, Perera 2009). These methods have proved to be relatively ineffective and expensive to implement because of the large areas in need of protection from elephants. The conflict areas are in some of the poorest parts of the world where communities are not able to protect themselves; therefore, innovative new methods are desperately needed to separate humans and elephants. The genetic relationship of the number and pattern of cropraiding elephants has previously been reported (Chiyo el al. 2011); this shows that methods should focus on altering the behavior of young, sexually mature adult males, which are separated from matriarchal family groups and responsible for the majority of crop depredations (Moss and Poole 1983, Sukumar and Gadil 1988, Sukumar 2003).

It is known that both long- and short-distance vocal communications play an important role in the complex social organization of elephants, enabling them to locate mates and maintain inter- and intra-group cohesion (Poole et al. 1988, Langbauer 2000, Garstang 2004, Nair et al. 2009, Soltis et al. 2009). The acoustic signals elephants emit are omnidirectional and can be broadcast to a wide audience, including listeners hidden from view. Elephants respond differently to a call depending on the identity of the caller, whether it is the matriarch or a subordinate animal, its age and dominance, and they can discriminate between the calls of conspecifics and different levels of social threat (McComb et al. 2000, 2001; Shannon et al. 2013). The complexity and specificity of these acoustic communications and their known ability to impact on elephant behavior indicates that selected vocalizations could be useful deterrents for elephants entering cultivated areas (Vollrath and DouglasHamilton 2002; Garstang 2004; King et al. 2007, 2010; Bittner 2008). 
Syntactically complex mammalian vocalizations have previously been studied in primates, cetaceans, bats, and recently in the rock hyrax (Procavia capensis; Kershenbaum et al. 2012), a mammal with close evolutionary relations to elephants (Hanak and Mazak 1979). The complexity and unique nature of elephant communication may relate to the elephant's aquatic ancestry (Gaeth et al. 1999). Previous studies of elephant vocal communications have shown that Asian elephants can comprehend and differentiate among calls of different individual elephants (Bittner 2008). It has also been found that elephant behavior can be manipulated by other natural sounds that threaten them (Vollrath and Douglas-Hamilton 2002; King et al. 2007, 2010; McComb et al. 2011; Thuppil and Coss 2013). The sound of disturbed African honeybees (Apis mellifera scutellata) elicited an alarm call from African elephants (King et al. 2010), which subsequently moved away from the sound. The presence of African honeybees also deters elephants from damaging the vegetation and trees that contain their hives. It has also been reported that wild Asian elephants can distinguish between aggressive tiger (Panthera tigris tigris) and leopard (P. pardus fusca) growls according to the perceived danger (Thuppil and Coss 2013). It has even recently been suggested that elephants can distinguish among different groups of humans and assess the threat that a person poses them based on acoustic cues in their voice (McComb et al. 2014).

We conducted playback experiments on wild adult male Asian elephants in Udewalawe National Park, Sri Lanka, in January 2011 using prerecorded wild Asian elephant vocalizations and the sounds of disturbed Sri Lankan hornets (Vespa affinis affinis). If it could be shown that playback of prerecorded sounds could scare wild elephants away from a food source, audio playback could become a new, humane way of reducing HEC in Sri Lanka and Southeast Asia.

\section{METHODS}

\section{Elephants}


We conducted playback experiments between 0900 and 1200 hours using wild adult male Asian elephants $(n=22)$ in Udewalawe National Park $(30,821$ ha), on the boundary of Sabaragamuwa and Uva provinces in Southern Sri Lanka. The study was carried out with the permission of Department of Wildlife Conservation (DWC) of Sri Lanka, under the Fauna and Flora Protection Ordinance, and in accordance with the guidelines of the American Society of Mammalogists (Gannon et al. 2007). The DWC was the government department responsible for maintaining national parks, nature reserves, and wildlife in wilderness areas in Sri Lanka.

We played each recording for 1 minute. We chose elephants for study at random when we located elephants along a stretch of electric fencing on the periphery of the National Park. We selected lone adult males for the study because they are the principal crop raiders. At each location, we took a photograph of each individual adult male and recorded any identifying features to ensure that it could be recognized if tested again. Once we located the adult male elephant, we provided food ad libitum to encourage the animal to remain in the experimental area. The food was a mixture of sugarcane, bananas, and palm fronds, which were readily available to wild elephants and known by locals to be favored by elephants. We set up a speaker system at a distance of approximately $10 \mathrm{~m}$ from the fence-line. We then placed the food source a further $5 \mathrm{~m}$ behind the fence-line to establish a standard distance between the speaker and the elephant for each playback. We recorded on video all behavioral responses of the elephants to the playbacks.

\section{Audio Recordings and Playback}

We divided the playback stimuli used into 4 categories: A) matriarchal family group vocalizations, B) disturbed Sri Lankan hornets, C) lone female elephant vocalizations, and D) a chainsaw as a control sound. The recording of the wild Asian elephant vocalizations (both A and C) were made in the Bandipura National Park and Tiger Reserve, Karnataka, India 
(Harrington 2004). The matriarchal group playback (A) consisted of multiple elephant calls including the matriarch and other subordinates. Recording A was made during an incident in which a female and her calf were separated from the main group, and they exchanged calls frequently with the matriarch until they were reunited, when they continued to vocalize; the lone female vocalizations (C) were recorded from a single animal (Harrington 2004). The sounds of disturbed Sri Lankan hornets (B) were recorded from a wild hornet colony in Kandy, Sri Lanka, using a recorder placed close to a swarming hornet's nest being removed by local pest-control workers. We played all sounds at a consistent volume through speakers directed at the experimental elephant.

We played the stimuli in a randomly selected order to each elephant. We played all 4 sounds to each elephant unless a flight response occurred, with a 5-minute interval between each sound to observe the elephant's response. If after the fourth playback there was no response from the elephant, we recorded a 'no response' and moved on to the next study animal. We recorded the order of playback to identify any evidence of habituation or accumulative effect of multiple playbacks on flight response. We also recorded the latency period between playback and response. During playback sessions, we played all sounds through a Sony 1500 speaker (Sony Corp., Minato, Tokyo, Japan; frequency range 25-10 $\mathrm{kHz}$ ) and an amplifier connected to a personal computer, and responses of the lone adult males were videoed using a Sony DCR-TRV and DRC-DVD 850E hand-held digital video recorder.

\section{Response Behavior}

We recorded behaviors and reactions during and after each playback. The objective of the study was to elicit a flight response from each individual adult male as a direct reaction to the sound played. We recorded the reaction of the elephants to the stimuli as either a flight response or a nonflight response. We defined a flight response as an adult male moving away 
from the food source into the surrounding jungle, out of sight from the investigators, and not returning to the same location for the remainder of the day. We defined a nonflight response as any other reaction, or lack thereof, not resulting in a flight response.

\section{Statistical Analysis}

We conducted this study on 22 tuskless adult male elephants that came into contact with the provided food source. In all, we conducted 48 playbacks on the 22 adult males, and classified reactions as either 'flight' or 'nonflight.' We considered any flight response with latency >60 seconds to be an outlier and removed it from the analysis. We then tested the statistical significance of each flight response using a chi-square test in Genstat (using either a yes or no criterion) of SAS Statistical Software (Version 9.3; SAS Institute, Inc., Cary, NC, USA). Flight response resulted in the animal being lost from the study, so not all sounds could be played to every adult male. We also analyzed playback order using chi-square to test for any effects of habituation. We used $\alpha=0.05$ in all statistical tests.

\section{RESULTS}

The playback of 4 distinct sounds (A-D) resulted in 14 flight responses during the 48 playback experiments conducted (Fig. 1). There was a clear and significant difference between each sound in its relation to eliciting a flight response $(A=11 / 17$ [65\%], $B=2 / 12$ [17\%], $\mathrm{C}=1 / 8[13 \%]$, and $\left.\overline{\mathrm{D}}=0 / 11 ; \chi_{3}^{2}=16.91, P<0.001\right)$. The reaction of elephants to sound A differed from all other sounds $\left(\chi_{3}^{2}=16.09, P<0.001\right)$. When A was removed from the analysis, there was no difference among sounds B, C and D in eliciting a flight response $\left(\chi_{3}^{2}=1.92, P=0.38\right)$. When testing for habituation, the observed results for each order of playback (1-4), regardless of sound played, was tested against the expected values and no effect of habituation was found $\left(\chi_{3}^{2}=0.94, P=0.71\right)$.

\section{DISCUSSION}


Our results provide the first direct evidence that playback of prerecorded sounds could scare wild Asian elephants away from a food source, suggesting that the provision of simple sound recordings may be an effective way to reduce HEC in Sri Lanka and Southeast Asia. The greatest response was to Sound A, which was the matriarchal family group. This was recorded in the Bandipura National Park and Tiger Reserve in Southern India, and consisted of multiple elephants vocalizing, including matriarchs and subordinates from a family group. The elephants were enjoying a water source when another family group sought access to it, causing the group to react with the recorded vocalizations. The adult male elephants reacted to these calls; therefore, this technique could be developed as a simple, cost-effective method for reducing HEC. This study showed that male elephants could recognize the sounds of female elephants, and distinguish between the call of a single female and a matriarchal family group. The most significant finding was the marked flight response of lone adult male elephants to sound A - matriarchal family group vocalizations. The ability to recognize different sounds of female elephants has been shown in previous research (Ross 2006, Bittner 2008).

Male elephants leave the family group at sexual maturity and only return to mate (Moss and Poole 1983). Despite the larger physical size of adult males, this return can be a dangerous journey because females will not tolerate the presence of a solitary male for any longer than necessary (Sukumar 2003). It is therefore not surprising that solitary males would find the vocalizations of a matriarchal family group a major deterrent, while the vocalizations of a lone female are far less intimidating. Future experiments should be conducted using a greater variety of vocalizations and sounds, such as those of a big adult male in musth. The few adult males that were not deterred or did not have a flight response to the elephant vocalizations were the largest animals studied, and may have ignored matriarchal threat calls because they were the oldest and the most massive. 
Recent studies (Vollrath and Douglas-Hamilton 2002; Garstang 2004; King et al. 2007, 2010) and anecdotal evidence show that elephants are cautious of, and will flee from, swarming insects. The Sri Lankan hornet is an aggressive and intolerant predator, and is ready to attack anything moving near its nest. A hornet's nest is usually found in the branches of trees, and thus can easily be disturbed when elephants are moving through thick forest or feeding. The hornets may chase the elephant for several kilometers if disturbed. This type of attack is much more dangerous for the elephant than that of a larger predator because the hornet's small size allows it to sting more sensitive parts of the elephant such as the eyes and inside the ears or trunk. Although a relatively rare response, the responding elephants in our study may have previously been stung and thus learned to fear hornets. Those adult males that did respond to the hornet stimuli did so vigorously and showed clear discomfort, confirming that the response was learned from experience.

Our study clearly showed that young crop-raiding adult male elephants are deterred by matriarchal family group vocalizations. This means that playback of these sounds should be able to deter wild adult male elephants from entering human settlements, at least in the short term. This playback method could easily be applied in even the poorest communities. In a desperate attempt to deter elephants from crop-raiding, Sri Lankan farmers have even resorted to using 'hakka-patas' —small pressure mines concealed in fruits or vegetables that shatter the elephant's jaws when bitten (Fernando et al. 2011). Such measures will continue to be enforced unless cheaper, more efficient, and more humane methods can be developed; and hopefully the playback of appropriate vocalizations is one possible solution to this growing problem. However, further investigation is required to test for any habituation that might occur with the use of these methods.

\section{ACKNOWLEDGMENTS}

This study was partially supported by the NSF-Sri Lanka (Grant No. RG/2006/EB/03). 
MPBW was a Visiting Fellow in the Department of Zoology, University of Melbourne, Victoria 3010, Australia, under an Endeavour Executive Award (Grant No. 1901-2010), from the Department of Education, Employment and Workplace Relations of the Australian Government. Furthermore, the researchers would like to thank Dr. Ian Bland of the University of Melbourne for his help and assistance in the early days of this research, and Professor F. Dunshea for his assistance with the statistics. The study was also partially funded by the not-for-profit organization, A Future With Elephants (www.afuturewithelephants.org). There are no potential conflicts of interest. Authors wish to gratefully acknowledge the valuable comments and suggestions made by the editors and reviewers to improve the manuscript. We thank the Chairman and Staff of the Department of Wildlife Conservation of the Sri Lankan Government for providing permission and assistance in conducting the playback experiments.

\section{LITERATURE CITED}

Bittner, E. 2008. Asian elephant vocalizations. Thesis, University of Melbourne, Parkville, Victoria, Australia.

Chiyo, P. I., C. J. Moss, E. A. Archie, J. A. Hollister-Smith, and S. C. Alberts. 2011. Using molecular and observational techniques to estimate the number and raiding patterns of crop-raiding elephants. Journal of Applied Ecology 48:788-796.

Fernando, P., J. Jayewardene, T. Prasad, W. Hendavitharana, and J. Pastorini. 2011. Current status of Asian elephants in Sri Lanka. Gajaha 35:93-103.

Fernando, P., M. A. Kumar, A. C. Williams, E. Wikramanayake, T. Aziz, and S. M. Singh. 2008. Review of human-elephant conflict mitigation measures practiced in South Asia. World Wide Fund for Nature, Vaud, Switzerland. 
Gaeth, A. P., R. V. Short, and M. B. Renfree. 1999. The developing renal, reproductive, and respiratory systems of the African elephant suggest an aquatic ancestry. Proceedings of the National Academy of Sciences of the United States of America 96:5555-5558.

Gannon, W.L., Sikes, R.S. and the animal care and use committee of the American Society of Mammalogists. 2007. Guidelines of the American Society of Mammalogists for the use of wild mammals in research. Journal of Mammalogy 88:809-823.

Garstang, M. 2004. Long-distance, low-frequency elephant communication. Journal of Comparative Physiology A, Neuroethology, Sensory, Neural, and Behavioral Physiology 190:791-805.

Hanak, V., and V. Mazak. 1979. Hyraxes—a zoological puzzle. Select edition. Octopus Books, London, England, United Kingdom.

Harrington, H. 2004. Vocal communication and social behavior of wild Asian elephants (Elephas maximus) in Bandipura National Park, South India. Honour's Thesis, University of Melbourne, Parkville, Victoria, Australia.

International Union for Conservation of Nature [IUCN]. 2012. IUCN red list of threatened species. www.iucnredlist.org. Accessed 28 Jan 2012.

Kershenbaum, A., A. Ilany, L. Blaustein, and E. Geffen. 2012. Syntactic structure and geographical dialects in the songs of male rock hyraxes. Proceedings of the Royal Society B 279:2974-2981.

King, L. E., I. Douglas-Hamilton, and F. Vollrath. 2007. African elephants run from the sound of disturbed bees. Current Biology 17:R832-833.

King, L. E., J. Soltis, I. Douglas-Hamilton, A. Savage, and F. Vollrath. 2010. Bee threat elicits alarm call in African elephants. PLoS One 5:e10346.

Langbauer, W. R., Jr. 2000. Elephant communication. Zoo Biology 19:225-445. 
McComb, K., C. Moss, S. M. Durant, L. Baker, and S. Sayialel. 2001. Matriarchs as repositories of social knowledge in African elephants. Science 292:491-494.

McComb, K., C. Moss, S. Sayialel, and L. Baker. 2000. Unusually extensive networks of vocal recognition in African elephants. Animal Behaviour 59:1103-1109.

McComb, K., G. Shannon, S. M. Durant, K. Sayialel, R. Slotow, J. Poole, and C. Moss. 2011. Leadership in elephants: the adaptive value of age. Proceedings of the Royal Society B 278:3270-3276.

McComb, K., G. Shannon, K. N. Sayialel, and C. Moss. 2014. Elephants can determine ethnicity, gender, and age from acoustic cues in human voices. Proceedings of the National Academy of Sciences of the United States of America 111:5433-5438.

Moss, C. J., and J. H. Poole. 1983. Relationships and social structure of African elephants. Pages 315-325 in R. Hinde, editor. Primate social relationships: an integrated approach. Blackwell Scientific, London, England, United Kingdom.

Nair, S., R. Balakrishnan, C. S. Seelamantula, and R. Sukumar. 2009. Vocalizations of wild Asian elephants (Elephas maximus): structural classification and social context. Journal of the Acoustical Society of America 126:2768-2778.

Perera, B. M. A. O. 2009. The human-elephant conflict: a review of current status and mitigation methods. Gajaha 30:41-52.

Poole, J. H., K. Payne, W. R. Langbauer, Jr., and C. Moss. 1988. The social contexts of some very low frequency calls of African elephants. Behavioral Ecology and Sociobiology $22: 385-392$.

Population Reference Bureau. 2011. Data profile for United States \& international profiles: Sri Lanka. www.prb.org. Accessed 30 Jun 2011.

Ross, M. L. 2006. Rumble in the jungle: acoustic communication in Asian elephants (Elephas maximus). Thesis, University of Melbourne, Parkville, Victoria, Australia. 
Shannon, G., R. Slotow, S. M. Durant, K. N. Sayialel, J. Poole, C. Moss, and K. McComb.

2013. Effects of social disruption in elephants persist decades after culling. Frontiers in Zoology 10:62.

Soltis, J., K. A. Leighty, C. M. Wesolek, and A. Savage. 2009. The expression of affect in African elephant (Loxodonta africana) rumble vocalizations. Journal of Comparative Psychology 123:222-225.

Sooriyabandara, M. G. C. 2014. A game theoretic scrutiny to human elephant conflict. Journal of the Department of Wildlife Conservation 2:29-40.

Sukumar, R. 2003. The living elephants. Evolutionary Ecology, Behavior, and Conservation. First edition. Oxford University Press, Oxford, England, United Kingdom.

Sukumar, R., and M. Gadil. 1988. Male-female differences in foraging on crops by Asian elephants. Animal Behaviour 36:1233-1235.

Thuppil, V., and R. G. Coss. 2013. Wild Asian elephants distinguish aggressive tiger and leopard growls according to perceived danger. Biology Letters 9:20130518. http://dx.doi.org/10.1098/rsbl.2013.0518.

Vollrath, F., and I. Douglas-Hamilton. 2002. African bees to control African elephants. Naturwissenschaften 89:508-511.

Associate Editor: Breck.

Figure 1. The effectiveness of audio playbacks at deterring 22 wild adult male Asian elephants from a food source in Udewalawe National Park, on the boundary of Sabaragamuwa and Uva provinces in Southern Sri Lanka, January 2011. Flow chart of each individual playback and occurrence of flight response, with reactions to each sound: (A) matriarchal family group, (B) disturbed Sri Lankan hornet, (C) lone female elephant, and (D) chainsaw sound as a control. * Indicates significant difference in response $\chi_{2}=16.09, P<$ $0.001)$. 


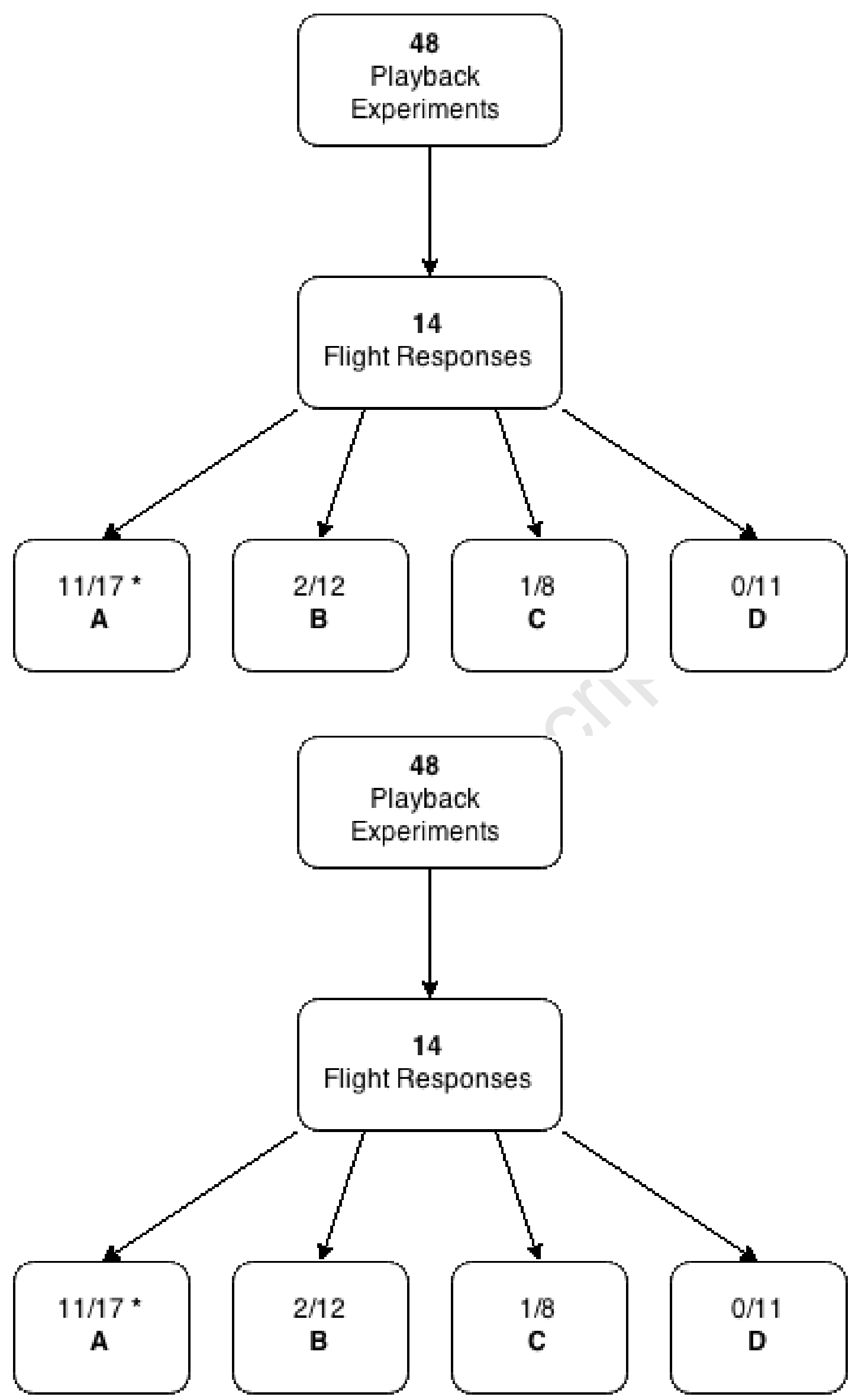




\section{University Library}

\section{- M M N E R VA A gateway to Melbourne's research publications}

Minerva Access is the Institutional Repository of The University of Melbourne

\section{Author/s:}

Wijayagunawardane, MPB;Short, RV;Samarakone, TS;Nishany, KBM;Harrington, H;Perera, BVP;Rassool, R;Bittner, EP

Title:

The Use of Audio Playback to Deter Crop-Raiding Asian Elephants

Date:

2016-06-01

\section{Citation:}

Wijayagunawardane, M. P. B., Short, R. V., Samarakone, T. S., Nishany, K. B. M., Harrington, H., Perera, B. V. P., Rassool, R. \& Bittner, E. P. (2016). The Use of Audio Playback to Deter Crop-Raiding Asian Elephants. WILDLIFE SOCIETY BULLETIN, 40 (2), pp.375-379. https:// doi.org/10.1002/wsb.652.

Persistent Link:

http://hdl.handle.net/11343/291215 